\title{
A digital climate summit to maintain Paris Agreement ambition
}

To the Editor - The COVID-19 pandemic is affecting the way we work, learn and interact with others. It is also changing how international politics is conducted. In early March, the European Council employed teleconferences to coordinate EU efforts to respond to the outbreak, the White House moved gatherings of the G7 online and the United Nations Security Council unanimously adopted four resolutions via e-mail for the first time in history.

The UNFCCC Secretariat also embraced teleconferencing for the March and April meetings, including the 17 th meeting of the Adaptation Committee and the 11th meeting of the Executive Committee of the Warsaw International Mechanism for Loss and Damage. However, Parties decided to postpone larger events, like the Bonn Climate Change Conference (SB 52) and the 26th Conference of the Parties to the UN Framework Convention on Climate Change (COP26) in Glasgow. Avoiding in-person gatherings is essential and widely welcomed, but this may be a missed opportunity to re-think the way climate diplomacy works and the role technology can play in it.

Moving negotiations online is technologically feasible. Teleconference products can offer collaborative workspaces for hundreds or even thousands of participants. The question is whether it is desirable, given the current configuration of climate talks. The digital divide between developed and developing countries can result in an additional source of power asymmetry within the UNFCCC process ${ }^{1}$. Moreover, as some commentators have noted $^{2}$, there are issues of real-time translation into the six UN languages, and the fact that the physical aspects of a negotiation - body language, interpersonal bonding, the mood of the room - greatly affect its outcomes. Research across political psychology, social neuroscience and International Relations shows that face-to-face diplomacy plays an important role in building trust and fostering international cooperation ${ }^{3}$. Against this background, it is difficult to see how States would give up traditional negotiations in order to have to grapple with issues of connectivity, language and the inability to physically intuit their counterparts' intentions.

We therefore suggest imagining a new format, which can maintain political momentum for climate action while ensuring participation from business, research and civil society. A digital COP26-Part 1 can serve this purpose. Parties are called to submit strengthened climate action plans - the Nationally Determined Contributions (NDCs) - and to publish long-term decarbonization strategies by 2020 . The UN Secretary-General Guterres further identified developing a robust package of resilience-developing initiatives, and provisioning of climate finance as priorities for COP26 (ref. ${ }^{4}$ ). All these outcomes do not need to be negotiated by Parties, and can be announced and discussed in a virtual space. Similarly, the rich programme of side-events, which characterizes COP each year, can be easily translated into video conferences. The digital COP would be a way to support climate ambition and complement, rather than substitute, COP26 next year.

The UNFCCC can learn from ongoing efforts to move in-person meetings online. The European Geosciences Union (EGU) has transformed its traditional General Assembly in Vienna to a virtual meeting that includes more than 17,000 abstracts and sets a model for minimizing the carbon footprint of future scientific conferences ${ }^{5}$. Similarly, organizers of the New York Climate week in September stated that the event will go ahead using video conferencing ${ }^{6}$. The digital transformation provides an unprecedented opportunity to open up the UNFCCC process and make it transparent and accessible to everyone.

When announcing the decision to delay COP26, the UNFCCC stated that this will allow Parties more time to prepare. Scientists, civil society representatives and policy-makers strongly suggested that the postponement of the climate talks should not translate into a postponement of ambitious climate action. We need to seize this unprecedented moment to redesign an annual conference to deliver in the fight against climate change.

\section{Elisa Calliari (1D),2,3凶, Jaroslav Mysiak (D) 2,3 and Lisa Vanhala \\ ${ }^{1}$ Department of Political Science \& School of Public Policy, University College London, London, UK. ${ }^{2}$ Centro Euro-Mediterraneo sui Cambiamenti Climatici, Venezia, Italy. ${ }^{3}$ Università Ca' Foscari Venezia, Venezia, Italy. \\ $凶_{e-m a i l: e . c a l l i a r i @ u c l . a c . u k}$}

Published online: 1 June 2020 https://doi.org/10.1038/s41558-020-0794-0

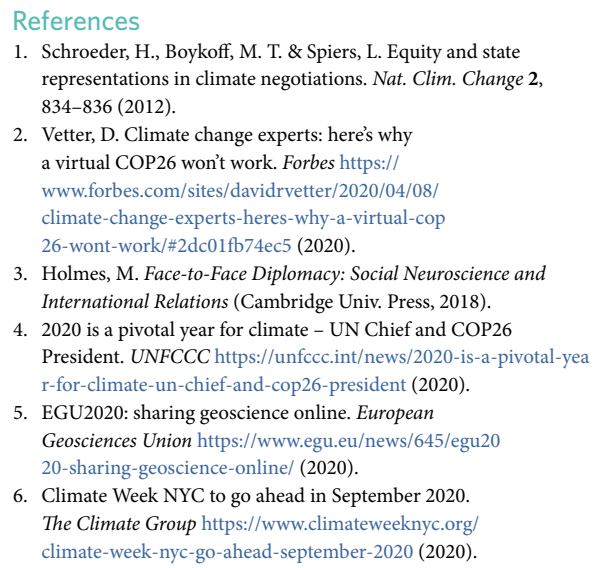

3. Holmes, M. Face-to-Face Diplomacy: Social Neuroscience and International Relations (Cambridge Univ. Press, 2018).

4. 2020 is a pivotal year for climate - UN Chief and COP26 President. UNFCCC https://unfccc.int/news/2020-is-a-pivotal-yea $r$-for-climate-un-chief-and-cop26-president (2020).

5. EGU2020: sharing geoscience online. European Geosciences Union https://www.egu.eu/news/645/egu20 20-sharing-geoscience-online/ (2020).

6. Climate Week NYC to go ahead in September 2020. The Climate Group https://www.climateweeknyc.org/ climate-week-nyc-go-ahead-september-2020 (2020).

\section{Acknowledgements}

This work was supported by the European Commission's Horizon 2020 Research \& Innovation programme under grant agreements nos. 755753 (The Politics of Climate Change Loss and Damage (CCLAD)) and 730482 (Climate forecast enabled knowledge services (CLARA)). 